\title{
Electrosynthesized polytyramine-copper oxalate nanocomposite on copper electrode for electrocatalytic oxidation of methanol in alkaline medium
}

\author{
Robab Abbasi a, Khalil Farhadi a,*, Sepideh Banisaeid a, Nader Nowroozi Pesyan a, Arezu Jamali a, \\ Fatemeh Rahmani ${ }^{b}$ \\ a Department of Analytical Chemistry, Faculty of Chemistry, Urmia University, Urmia, Iran \\ ${ }^{\mathrm{b}}$ Department of Biological Science, Faculty of Science, Urmia University, Urmia, Iran
}

\section{A R T I C L E I N F O}

\section{Article history:}

Received 5 December 2013

Accepted 26 January 2014

Published 20 July 2014

\section{Keywords:}

Polytyramine

Copper oxalate

Nanocomposite

Electropolymerization

Copper modified electrode

Electrocatalytic oxidation

Methanol

\begin{abstract}
A B S T R A C T
A polytyramine-copper oxalate nanocomposite modified copper (PTCOxNMC) electrode prepared by electropolymerization was examined for electrocatalytic activity towards the oxidation of methanol in alkaline solution using cyclic voltammetry and impedance spectroscopy. The prepared PTCOxNMC electrode showed a significantly high response for adsorbed methanol oxidation. The effects of various parameters such as potential scan rate and methanol concentration on the electrocatalytic oxidation at the surface of the PTCOxNMC electrode were investigated. Spectrometry techniques such as Fourier transform infrared spectroscopy and scanning electron microscopy were used to determine the surface physical characteristics of the modified electrode and revealed that the polytyramine-copper oxalate nanocomposite particles were highly dispersed on the surface of the copper electrode with a narrow size up to $40 \mathrm{~nm}$. The very high current density obtained for the catalytic oxidation may have resulted from the high electrode surface area caused by modification with the poly-tyramine-copper oxalate nanocomposite.
\end{abstract}

(C) 2014, Dalian Institute of Chemical Physics, Chinese Academy of Sciences. Published by Elsevier B.V. All rights reserved.

\section{Introduction}

Direct methanol fuel cells (DMFCs) are considered to be promising candidates for portable device and vehicle applications due to their high energy density, easy manipulation, and high efficiency. From a technical point of view, the low activity, high cost, and poor stability of the anode catalysts toward methanol electrooxidation still hinder the commercialization of DMFCs [1]. One of the problems still unsolved is the slow kinetics of the anodic methanol oxidation [2]. The electrocatalytic oxidation of methanol has been studied on various electrodes, including Pt [3-5], binary and ternary alloys [6-10], modified electrodes [11-14], nanocomposites [15-18], and nickel
[19-23]. Although metals such as Pt, Au, and Ag are very active for the anodic oxidation and cathodic reduction, they are too expensive for practical application [24]. Moreover, considerable efforts have been directed toward the study of methanol electrooxidation in solutions of high $\mathrm{pH}$. The use of alkaline solutions in a fuel cell has many advantages such as increased overall efficiency, a wider selection of possible electrode materials, higher efficiency of both anodic and cathodic processes, almost no sensitivity to the surface structure, and negligible poisoning effects in alkaline solutions [25]. Hence, a great deal of interest has recently been focused on the use of non-noble transition metals in alkaline media [2,26-31].

Copper is a widely used reactive metal because of its low re- 
sistivity and good electro-migration performance [32]; however, it is an active metal that does not resist corrosion well. Much attention is focused on the modification of the copper surface for two goals: (1) formation of a stable layer to protect the electrode from corrosion and (2) formation of an electrocatalytic layer to enhance the electrochemical properties of the electrode [33].

Polymer coating of electrodes can be differentiated from other modification methods such as adsorption and covalent bonding. The resulting thicker films imply more active sites, which leads to larger analytical signals [25]. In addition, the recent development of conducting polymeric nanoparticle-based corrosion inhibitors with self-cleaning properties, and high scratch as well as wear resistance is expected to cause a major revolution in the world of corrosion [34]. Because the dissolution of oxidizable metals like copper occurs at lower potentials than the monomer oxidation potential, the metal must be passivated to generate a suitable surface prior to the electropolymerization of electroactive specimens [35].

In the present work, with the main goal of introducing a new modifier layer for cheap metals, we illustrate that it is possible to obtain homogeneous and adherent polytyramine-copper oxalate nanocomposite (PTCOxN) on a copper electrode. For this purpose, tyramine was electropolymerized on a copper electrode initially passivated in oxalic acid medium. Once the copper was passivated, the electropolymerization of tyramine was performed using different techniques to obtain well-dispersed nanoparticles (40 nm) of uniform size and superior adhesion. The efficiency of the polytyramine-copper oxalate nanocomposite modified copper (PTCOxNMC) electrode toward the electrocatalytic oxidation of methanol in alkaline medium was investigated. The obtained results show that this modified electrode has an excellent electrocatalytic power with high oxidation current density in the electrooxidation of methanol.

\section{Experimental}

\subsection{Reagents and instrumentation}

Tyramine was used as received from Sigma Aldrich. All other reagents were of analytical grade and were used without further purification; doubly distilled water was used in the preparation of all solutions.

Electrochemical studies were performed at room temperature using an electrochemical system comprising an Autolab PGSTAT30 potentiostat/galvanostat with pilot integration controlled by GPES 4.9 software in a three-compartment cell. Electrochemical impedance spectroscopy (EIS) was carried out at frequencies between $100 \mathrm{kHz}$ and $0.1 \mathrm{~Hz}$ using the same equipment as that described above. A dual Ag-AgCl saturated $\mathrm{KCl}$ electrode, stainless steel (SS) flag, and a copper rod were used as the reference, counter, and working electrodes, respectively. The morphology of the deposits was determined using a Philips XL30 low vacuum scanning electron microscope. Fourier transform infrared (FT-IR) transmission spectra were recorded in horizontally attenuated total reflectance (HATR) mode in the spectral range $4000-500 \mathrm{~cm}^{-1}$ using a Thermonicolet (Nexus 670) FT-IR spectrometer.

\subsection{Electrode preparation}

The working electrode was made of a copper rod covered with Teflon tape with a disk diameter of $3 \mathrm{~mm}$. Before use, the electrode was polished with a series of emery papers, followed by thorough rinsing in acetone and double distilled water, and dried in air. The copper working electrode was passivated in $0.3 \mathrm{~mol} / \mathrm{L}$ oxalic acid solution through five potential scans between -0.3 and $+1.4 \mathrm{~V}$ at a scan rate of $4 \mathrm{mV} / \mathrm{s}$. After passivation, electropolymerization was performed using consecutive cyclic voltammetry (for 10 cycles) between -0.3 and $1.3 \mathrm{~V}$ at potential scan rate of $10 \mathrm{mV} / \mathrm{s}$ in a solution containing 0.3 mol/L oxalic acid and $0.01 \mathrm{~mol} / \mathrm{L}$ tyramine. The modified copper electrode was rinsed with distilled water and dried with nitrogen gas prior to any experiment.

\section{Results and discussion}

\subsection{Preparation of polytyramine-copper oxalate nanocomposite modified copper (PTCOxNMC) electrode}

Our preliminary studies on the polymerization of tyramine on a copper electrode showed that the synthesized polytyramine (PT) is not a uniform and stable layer. Therefore, the electropolymerization process was performed on a passivated copper electrode. Figure 1 shows the recorded five consecutive cyclic voltammograms on the pristine copper electrode in the presence of $0.3 \mathrm{~mol} / \mathrm{L}$ oxalic acid solution at potential scan rate of $4 \mathrm{mV} / \mathrm{s}$. In the first cycle, an intensive anodic peak appears about $0.112 \mathrm{~V}$ vs $\mathrm{Ag} / \mathrm{AgCl}$, which is probably related to the dissolution of copper. A clear decrease in the intensity of the obtained anodic peak currents in the subsequent cycles confirms a decrease in copper dissolution as well as formation of a good passive layer on the copper electrode. The passivation of copper electrodes in oxalic acid medium has previously been reported in the literature [36,37]. Herrasti et al. [38] explained the composition and mechanism of copper passivation in oxalic

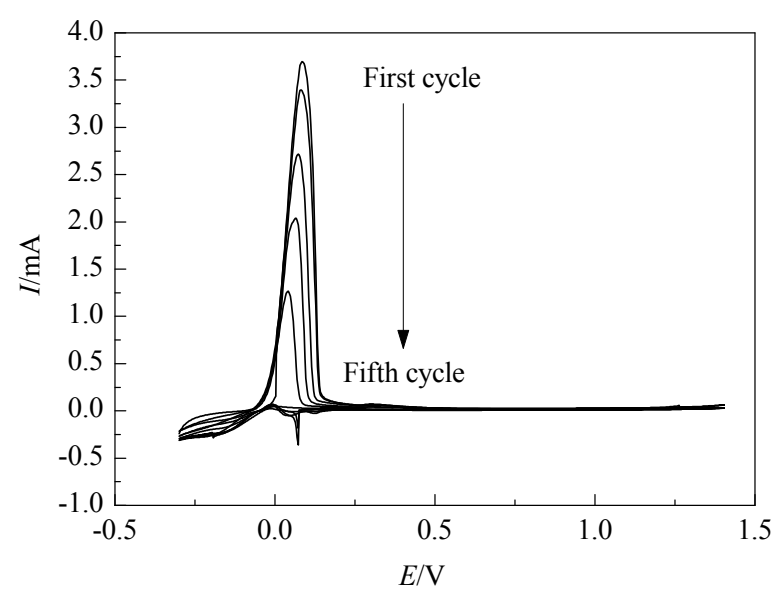

Fig. 1. Cyclic voltammograms recorded in $0.3 \mathrm{~mol} / \mathrm{L}$ oxalic acid for the copper working electrode (five cycles). Scan rate: $4 \mathrm{mV} / \mathrm{s}$. 


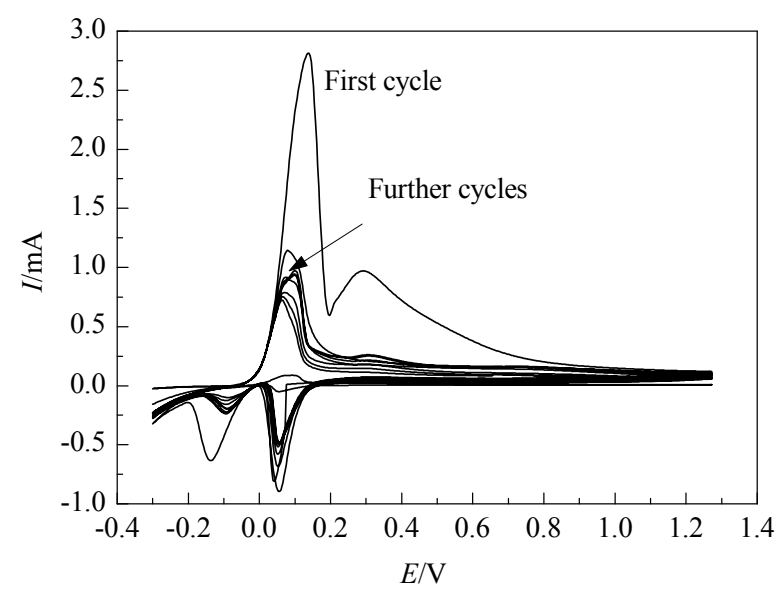

Fig. 2. Cyclic voltammograms recorded in $0.3 \mathrm{~mol} / \mathrm{L}$ oxalic acid +0.1 $\mathrm{mol} / \mathrm{L}$ tyramine at scan rate $10 \mathrm{mV} / \mathrm{s}$.

acid solutions through the formation of $\mathrm{Cu}(\mathrm{Ox})$ and $\left[\mathrm{Cu}(\mathrm{Ox})_{2}\right]^{2-}$ complexes on the surface of copper electrodes.

After the passivation of copper electrode, the electropolymerization of tyramine in solution is possible with negligible change in conditions. Figure 2 shows the 10 consecutive cyclic voltammograms obtained during the electropolymerization of tyramine on the passivated copper electrode between -0.3 and $1.3 \mathrm{~V}$ vs Ag-AgCl reference electrode at potential scan rate of 10 $\mathrm{mV} / \mathrm{s}$. In the first forward scan, the irreversible peak at approximately $0.29 \mathrm{~V}$ is associated with the electrodissolution of copper, but in subsequent cycles, dissolution at this potential is inhibited. Also, a well-defined redox pairs peaks at around $+0.14 \mathrm{~V}$ is related to oxidation/reduction of the monomer. As the polymer film thickness increases with the number of cycles, the surface becomes more protected, and the oxidation peak becomes smaller and shifts to more negative potential than the previous one.

Scheme 1 describes a pathway for the polymerization of tyramine via anodic oxidation. Because the amino function in the tyramine structure is separated from the phenolic ring by two methylene groups, it is expected that, similar to other phenols, only the phenol moiety in ortho position is oxidized to perform the polymerization [39].

\subsection{Spectroscopic characterization of PT films}

Comparison of the FT-IR spectra of bare, passivated, and PT

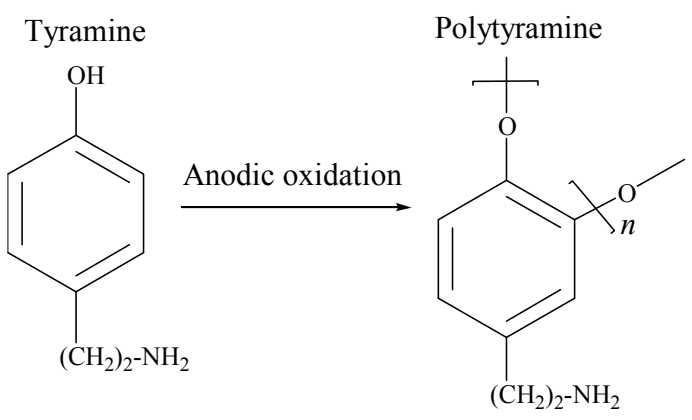

Scheme 1. Schematic of the electrooxidation/polymerization of tyramine to polytyramine.

coated copper electrodes showed the presence of carboxylate functional groups on the passivated and PT modified copper electrodes at 1584 and $1466 \mathrm{~cm}^{-1}$. Also, the bands displayed in the spectrum of the PT coated copper electrodes at 3433, 3401, 1362 , and $817 \mathrm{~cm}^{-1}$ proved the presence of $\mathrm{N}-\mathrm{H}$ and $\mathrm{C}-\mathrm{N}$ groups, which is characteristic of para-di-substituted aromatic rings and confirms the formation of PT on the copper electrode.

Figure 3(a-c) shows the scanning electron micrographs of the bare, passivated, and PT coated copper electrodes, respectively. As seen, after passivation, the striations caused by grinding are covered by compacted spherical oxalate grains with an average size of approximately $35.16 \mathrm{~nm}$ (Fig. 3(b)). Electropolymerization of tyramine forms a homogenous and defect-free thin layer on the copper oxalate grains (Fig. 3(c)), which indicates the $\mathrm{Cu} / \mathrm{Ox} / \mathrm{PT}$ arrangement nanoparticles are stable and have average size of approximately $39.84 \mathrm{~nm}$.

\subsection{Electrocatalytic oxidation of methanol at PTCOxNMC electrode}

Figure 4 shows the voltammograms of bare, oxalate passivated, and polytyramine-copper oxalate nanocomposite modified copper electrodes recorded in $0.1 \mathrm{~mol} / \mathrm{L} \mathrm{NaOH}$ solution containing $0.1 \mathrm{~mol} / \mathrm{L}$ methanol in the potential range -0.2 to 1 $\mathrm{V}$ at a scan rate of $20 \mathrm{mV} / \mathrm{s}$. In the absence of methanol and at the bare copper electrode, because of restriction on the negative limit of potential sweep, the background current markedly decreases, and no significant peak except the one due to the oxidation of $\mathrm{Cu}^{\mathrm{II}}$ to $\mathrm{Cu}^{\mathrm{III}}$ is observed [2]. In the presence of methanol (Fig. 4(1)), the oxidation of $\mathrm{Cu}^{\mathrm{II}}$ to $\mathrm{Cu}^{\mathrm{III}}$ shifts to a more negative potential $(0.70 \mathrm{~V})$, which is completely in ac-
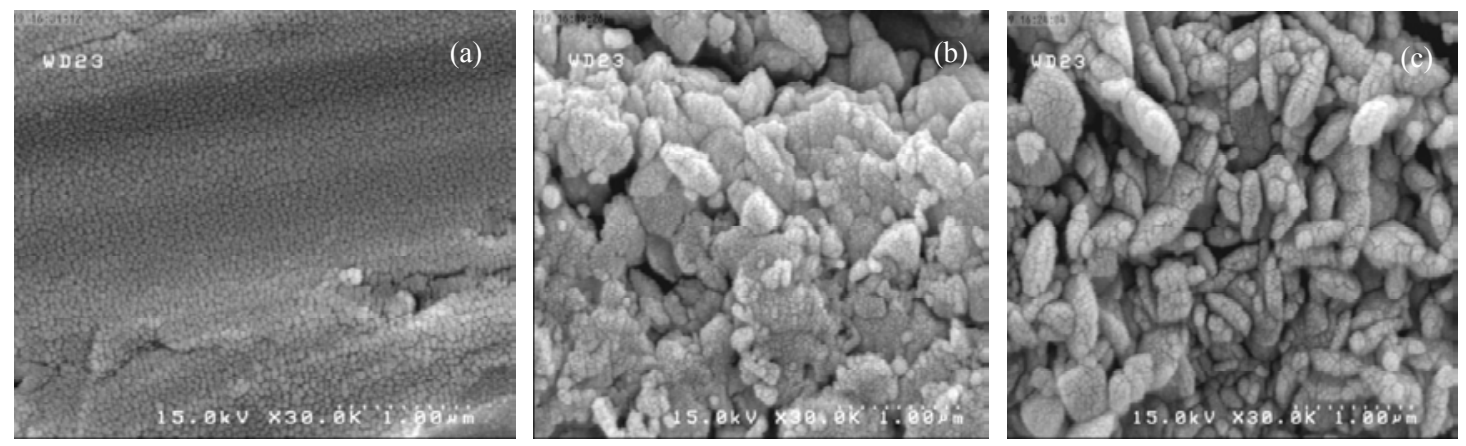

Fig. 3. SEM images of bare $\mathrm{Cu}(\mathrm{a})$, passivated $\mathrm{Cu}(\mathrm{Cu} / \mathrm{Ox})(\mathrm{b})$, and PT coated copper $(\mathrm{Cu} / \mathrm{Ox} / \mathrm{PT})(\mathrm{c})$ electrodes. 


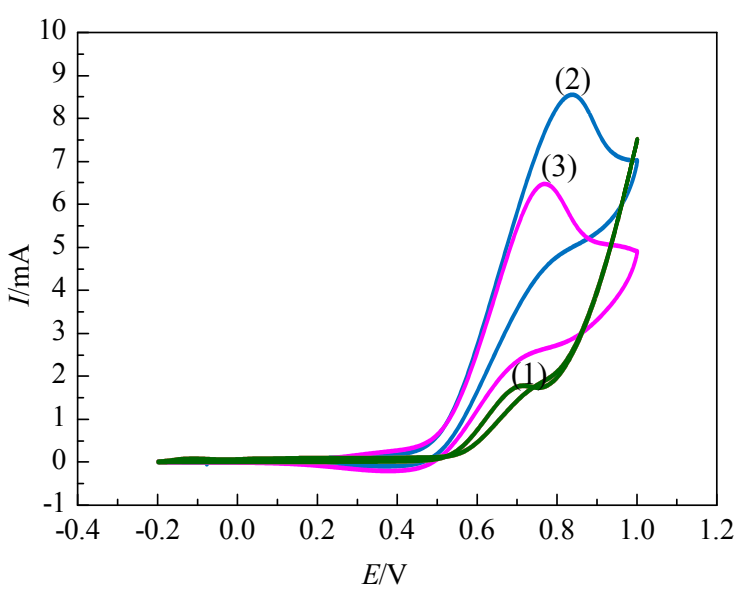

Fig. 4. Cyclic voltammetric responses of various copper electrodes in $0.1 \mathrm{~mol} / \mathrm{L} \mathrm{NaOH}$ solution containing $0.1 \mathrm{~mol} / \mathrm{L}$ methanol at scan rate 20 $\mathrm{mV} / \mathrm{s}$. (1) Bare electrode; (2) Oxalate passivated electrode; (3) PTCOxNMC.

cordance with an electrochemical-chemical (EC') mechanism and is in agreement with those reported in the literature [2,40-42]. According to this electrocatalytic oxidation mechanism, $\mathrm{Cu}^{\mathrm{III}}$ acts as a redox mediator for the chemical oxidation of adsorbed methanol in alkaline solutions:

$$
\begin{gathered}
\mathrm{Cu}(\mathrm{II}) \leftrightarrows \mathrm{Cu}(\mathrm{III})+\mathrm{e} \\
\mathrm{Cu}(\mathrm{III})+\mathrm{CH}_{3} \mathrm{OH}_{\text {ads }} \rightarrow \mathrm{Cu}(\mathrm{II})+\text { product }
\end{gathered}
$$

It should be noted that methanol is not an electroactive species at copper electrodes at low potentials, and methanol chemically adsorbed on copper electrodes is oxidized at more positive potentials [43]. Figure 4(2) illustrates the electrocatalytic oxidation of methanol at the oxalate passivated copper electrode. As seen, the electrocatalytic process with oxalate salts of $\mathrm{Cu}$ III $/ \mathrm{Cu}^{\mathrm{II}}$ mediator occurs with high intensity at more positive potentials (about $0.8 \mathrm{~V}$ ) in comparison with the copper oxide mediators formed on the bare copper electrode, probably due to high adsorption tendency of methanol toward oxalate salts. After deposition of the PT layer on the copper oxalate nanoparticles (Fig. 4(3)), the intensity of the mediator peak decreases in comparison with that for the copper oxalate passivated electrode but appears at a more negative potential of about $0.72 \mathrm{~V}$. Further experiments indicated that the electrocatalytic peak current intensity increases with accumulation time at a low concentration of methanol. These results confirm the existence of a specific adsorption between methanol and the polytyramine-copper oxalate nanocomposite. Moreover, to assess more reasons for such a claim, the relationship between the oxidation peak current and concentration of methanol on a PTCOxNMC electrode was studied (cyclic voltammograms not shown here). The obtained results are shown in Fig. 5. As seen, the peak height increases linearly with methanol concentration up to $0.07 \mathrm{~mol} / \mathrm{L}$, and no significant increase in peak intensity is observed at higher concentrations of methanol. This result once more is completely in accordance with a specific adsorption between methanol and the polytyramine-copper oxalate nanocomposite particles. On the other hand, it can also be assumed that the increase is due to the presence of a diffusion controlled process that appears to play an important role at

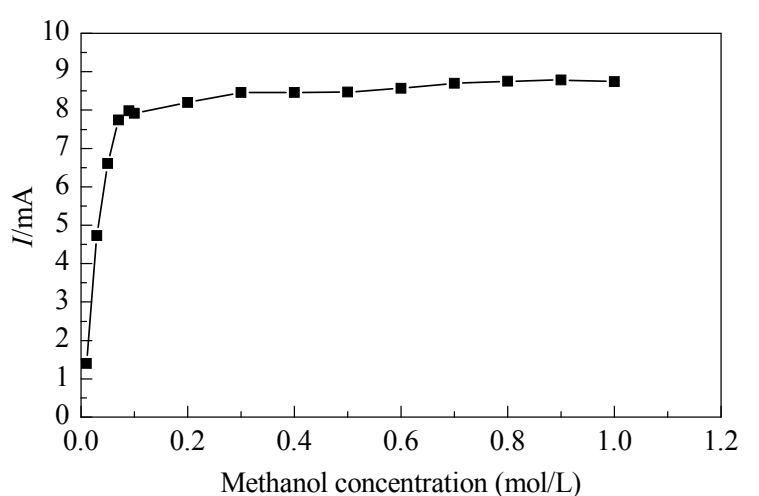

Fig. 5. Plot of anodic peak current as a function of methanol concentration.

low methanol concentrations. While the methanol concentration exceeds this limit, the rate of the whole oxidation process seems to be limited by that of the catalytic process [44,45], indicating that only adsorbed methanol is electrooxidized. Similar behavior has been observed on other modified electrodes $[46,47]$. As an overall conclusion, the increased activity is probably related to a more favorable or specific adsorption of reactant or of intermediates leading to a higher surface concentration of electroactive molecules ready to be oxidized, or is due to the partial delocalization of the electronic density of methanol into the solid with possible consequent bond pre-dissociations, which facilitates the oxidation, or both. Furthermore, the great improvement in the oxidation of methanol can be attributed to the large area and number of active sites for adsorption and electrocatalytic oxidation of methanol on the PTCOxNMC electrode in comparison with the bare copper electrode. This proves that the polymer layer formed on the surface of the copper oxalate reduces the specific adsorption tendency of methanol molecules towards copper oxalate nanoparticles and has a main role in the electrocatalytic oxidation of methanol on the surface of the PTCOxNMC electrode.

The stability of the polytyramine layer was very high, so that the proposed electrode showed reproducible responses in terms of both current and potential after the recording of more than 100 cyclic voltammograms. Moreover, the response of the electrode showed negligible changes in potential and current after two months kept dry at room temperature in air.

\subsection{Effect of scan rate}

Cyclic voltammograms of the PTCOxNMC electrode in 0.1 mol/L methanol solution in a range of $2-100 \mathrm{mV} / \mathrm{s}$ are illustrated in Fig. 6(a). As it can be seen, the anodic peak potential shifted to more positive potential with increasing scan rate, suggesting a kinetic limitation in the reaction between the redox sites of the PTCOxNMC electrode and methanol. However, the electrocatalytic oxidation current of methanol linearly increased with the square root of the potential scan rate (Fig. 6(b)), which demonstrates that the reaction is diffusion controlled. Moreover, plotting the current function against the potential sweep rate revealed a negative slope, confirming the electrocatalytic nature of the process (Fig. 7(a)), and a plot of 

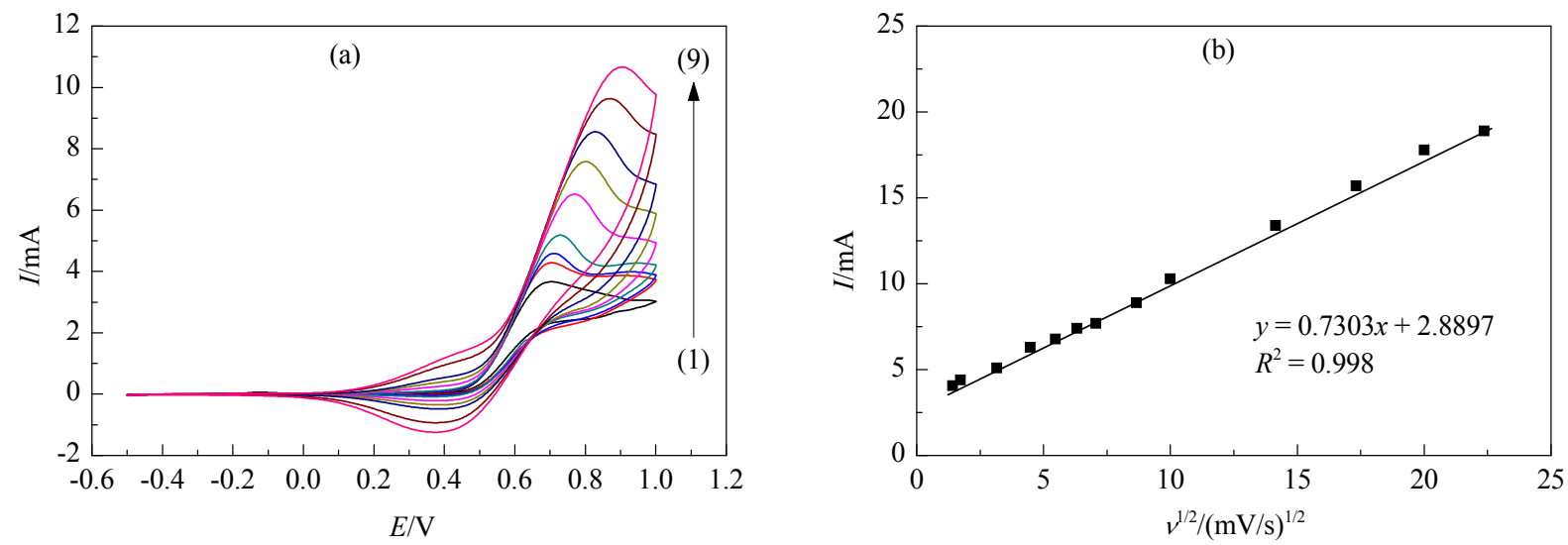

Fig. 6. (a) Dependence of the cyclic voltammetric response at the PTCOxNMC electrode on sweep rate in $0.1 \mathrm{~mol} / \mathrm{L} \mathrm{NaOH}$ containing $0.1 \mathrm{~mol} / \mathrm{L}$ methanol. (1-9) Scan rate: 2, 5, 7, 10, 20, 30, 40, 75, $100 \mathrm{mV} / \mathrm{s}$. (b) Variation of catalytic current with the square root of the sweep rate for scan rates of $2-500 \mathrm{mV} / \mathrm{s}$.
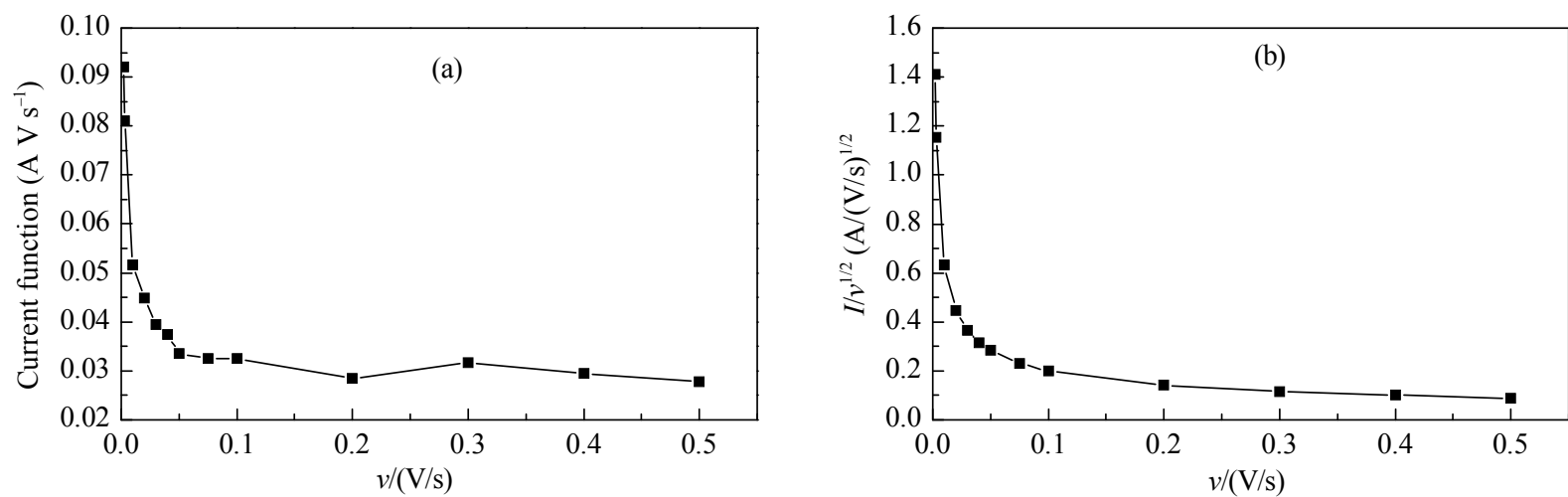

Fig. 7. Current function (a) and anodic current function $\left(I / v^{1 / 2}\right)$ (b) vs potential sweep rate $(v)$ for $0.1 \mathrm{~mol} / \mathrm{L} \mathrm{NaOH}$ solution in the presence of 0.1 $\mathrm{mol} / \mathrm{L}$ methanol.

the scan rate-normalized current $\left(I / v^{1 / 2}\right)$ with respect to scan rate (Fig. 7(b)) exhibited the typical shape of an electrochemical-chemical (EC') catalytic processe [48].

\subsection{Impedance spectroscopy of methanol electrooxidation}

Figure 8 shows the Nyquist plots of the copper and PTCOxNMC electrodes recorded in the $0.1 \mathrm{~mol} / \mathrm{L} \mathrm{NaOH}+0.1$ $\mathrm{mol} / \mathrm{L} \mathrm{CH}_{3} \mathrm{OH}$ solution at $0.75 \mathrm{~V}$. As seen from Fig. 8, the diameter of the impedance arc (DIA) decreases in order to $\mathrm{Cu}$ and PTCOxNMC electrodes. This indicates that the value of the charge transfer resistance $\left(R_{\mathrm{ct}}\right)$ of the PTCOxNMC electrode was much smaller than that of the copper electrode, confirming a faster electron transfer process on the polymeric modified electrode than that on the bare copper electrode. This result may be related to the higher real surface of the PTCOxNMC electrode surface and also to the better electron conductivity of the PTN-copper oxalate support, which probably releases oxalate ions during the electrocatalytic process. Thus, the polymeric modified electrode shows a much higher catalytic activity for methanol oxidation than the bare electrode.

For further study, the proposed equivalent circuits of the EIS data are shown as insets of Fig. 8. Here, $R_{\mathrm{s}}, R_{\mathrm{c}}$, and $R_{\mathrm{ct}}$ are the solution, coating, and charge transfer resistances, respectively. A constant phase element (CPE) is attributed to a charge transfer process replacing the double layer capacity $\left(C_{\mathrm{dl}}\right)$. In equivalent circuits, CPEe and CPEc are the constant phase elements of the electrode and coating, respectively. The experimental EIS data for the bare copper electrode are completely fitted by Randles circuit [49]. In this circuit, the impedance of a

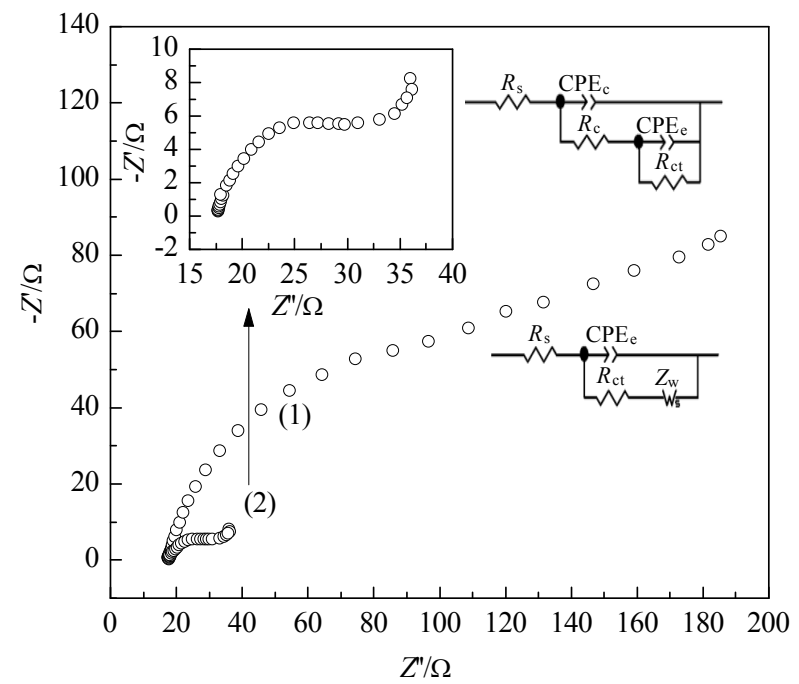

Fig. 8. Nyquist plots of EIS for methanol electrooxidation on copper electrode (1) and PTCOxNMC (2) electrode in $0.1 \mathrm{~mol} / \mathrm{L} \mathrm{NaOH}+0.1$ $\mathrm{mol} / \mathrm{L} \mathrm{CH}_{3} \mathrm{OH}$ solution at $0.75 \mathrm{~V}$. 
Faradaic reaction consists of an active charge transfer resistance $R_{\mathrm{ct}}$ and a specific electrochemical element of diffusion $Z_{\mathrm{w}}$ (Warburg element). It must be noted that no Warburg impedance was observed in the EIS data of the coated copper electrode. The $\log \left(R_{\mathrm{ct}} / \Omega\right)$ of methanol oxidation on copper and PTCOxNMC electrodes at $0.75 \mathrm{~V}$ vs $\mathrm{Ag} / \mathrm{AgCl}$ were obtained as 3.2 and 2.5, respectively, from the fitting with the equivalent circuits. As seen, the $R_{\mathrm{ct}}$ on the PTCOxNMC electrode is smaller than that on the bare copper electrode, indicating that the electron transfer kinetics for the electrooxidation of methanol are much better facilitated on the present polymeric modified copper electrode.

\section{Conclusions}

Copper can be made a suitable electrode for the electrooxidation of methanol by preventing its corrosion by passivating its surface, creating active areas on its surface, and increasing its surface area. A PTCOxNMC electrode was prepared by electropolymerization of tyramine in the presence of oxalate ions using a cyclic voltammetry technique. The surface adsorption of methanol toward polytyramine-copper oxalate nanocomposite particles is very high so that methanol oxidation occurs with high current density in comparison with bare copper electrode. The anodic peak current for methanol oxidation at the PTCOxNMC electrode is linearly proportional to the square root of scan rate, which is an indication of a diffusion-controlled reaction. Moreover, the plot of the scan rate-normalized current with respect to scan rate shows an electrocatalytic reaction. The electro-oxidation of methanol occurs through an electron transfer mechanism mediated by $\mathrm{Cu}^{\mathrm{III}}$ species. Although the electrocatalytic peak current is slightly diminished by adding the polytyramine layer to the copper oxalate particles, the following improvements are obtained: (1) The potential peak shifts towards more negative potential in comparison with copper oxalate passivated electrode; (2) The polymer layer acts as a second inhibitor preventing corrosion of the copper; (3) The polymer layer prevents the bleeding of copper oxalate and increases the lifetime of the proposed electrode; (4) The polymer layer leads to reproducible responses. So, it can be stated that the polytyramine layer formed on the surface of the electrode improves the characteristics of the passivated copper electrode for the electrocatalytic oxidation of methanol.

\section{References}

[1] Yao S K, Feng L, Zhao X, Liu C P, Xing W. J Power Sources, 2012, 217: 280

[2] Heli H, Jafarian M, Mahjani M G, Gobal F. Electrochim Acta, 2004, 49: 4999

[3] Nonaka H, Matsumura Y.J Electroanal Chem, 2002, 520: 101

[4] Zeng J H, Shu T, Liao S J, Liang Z X. Chin J Catal (曾建皇, 舒婷, 廖 世军, 梁振兴. 催化学报), 2011, 32: 86

[5] Chen Y G, Zhuang L, Lu J T. Chin J Catal (陈西贵, 庄林, 陆君涛. 催 化学报), 2007, 28: 870

[6] Green C L, Kucernak A. J Phys Chem B, 2002, 106: 1036

[7] Arico A S, Poltarzewski Z, Kim H, Morana A, Giordano N, Antonucci V. J Power Sources, 1995, 55: 159

[8] Danaee I, Jafarian M, Mirzapoor A, Gobal F, Mahjani M G. Electrochim Acta, 2010, 55: 2093

[9] Soszko M, Łukaszewski M, Mianowska Z, Czerwinski A. J Power Sources, 2011, 196: 3513

[10] Cai S F, Wang D S, Niu Z Q, Li Y D. Chin J Catal (蔡双飞, 王定胜, 牛 志强, 李亚栋. 催化学报), 2013, 34: 1964

[11] Jafarian M, Mahjani M G, Heli H, Gobal F, Khajesharifi H, Hamedi M H. Electrochim Acta, 2003, 48: 3423

[12] Golabi S M, Nozad A. Electroanalysis, 2003, 15: 278

[13] Yin S B, Zhu Q Q Qiang Y H, Luo L. Chin J Catal (尹诗斌, 朱强强, 强颖怀, 罗林. 催化学报), 2012, 33: 290

[14] Karim-Nezhad G, Pashazadeh S, Pashazadeh A. Chin J Catal (催化

\section{Graphical Abstract}

Chin. J. Catal., 2014, 35: 1098-1104～doi: 10.1016/S1872-2067(14)60049-8

Electrosynthesized polytyramine-copper oxalate nanocomposite on copper electrode for electrocatalytic oxidation of methanol in alkaline medium

Robab Abbasi, Khalil Farhadi*, Sepideh Banisaeid, Nader Nowroozi Pesyan, Arezu Jamali, Fatemeh Rahmani Urmia University, Iran
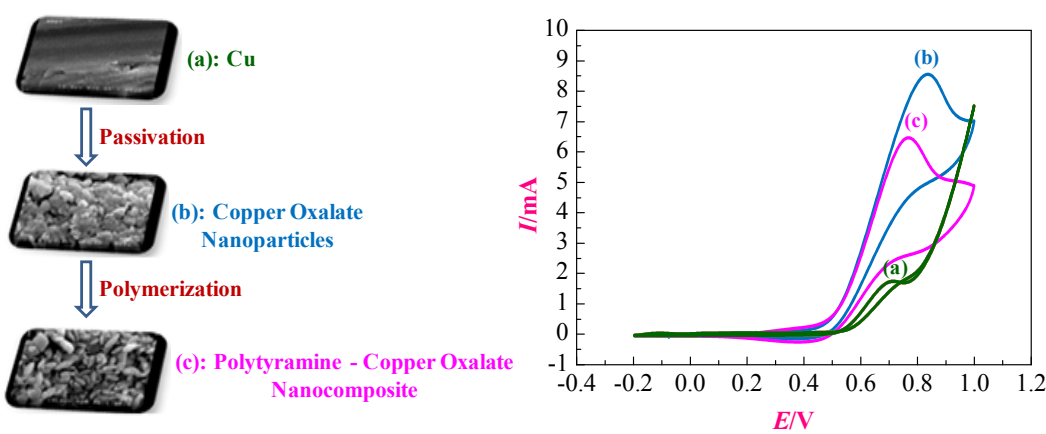

This paper describes the use of a polytyramine-copper oxalate nanocomposite formed on a copper electrode as a suitable mediator for electrocatalytic oxidation of methanol in alkaline medium as well as a surface corrosion inhibitor. 
学报), 2012, 33: 1809

[15] Jones F E III, Milen S B, Gurau B, Smotkin E S, Stock S R, Lukehart C M. J Nanosci Nanotechnol, 2002, 2: 81

[16] Luo J, Maye M M, Lou Y B, Han L, Hepel M, Zhong C J. Catal Today, 2002, 77: 127

[17] Lu X F, Zhang W J, Wang C, Wen T C, Wei Y. Prog Polym Sci, 2011, 36: 671

[18] Awasthi R, Singh R N. Int J Hydrogen Energy, 2012, 37: 2103

[19] El-Shafei A A.J Electroanal Chem, 1999, 471: 89

[20] Kim M S, Hwang T S, Kim K B. J Electrochem Soc, 1997, 144: 151

[21] Ojani R, Raoof J B, Hosseini Zavvarmahalleh S R. Electrochim Acta, 2008, 53: 2402

[22] Abdel Rahim M A, Abdel Hameed R M, Khalil M W.J Power Sources, 2004, 134: 160

[23] Hosseini M G, Abdolmaleki M, Ashrafpoor S. Chin J Catal (催化学 报), 2013, 34: 1712

[24] Karim-Nezhad Gh, Zare Dizajdizi B, Seyed Dorraji P. Catal Commun, 2011, 12: 906

[25] Ojani R, Raoof J B, Ahmady-Khanghah Y. Electrochim Acta, 2011, 56: 3380

[26] Li Z, Meng F H, Ren J, Zheng H Y, Xie K C. Chin J Catal (李忠, 孟凡 会, 任军, 郑华艳, 谢克昌. 催化学报), 2008, 29: 643

[27] Hasanzadeh M, Karim-Nezhad G, Mahjani M G, Jafarian M, Shadjou N, Khalilzadeh B, Saghatforoush L A. Catal Commun, 2008, 10: 295

[28] Nagy L, Nagy G, Hajos P. Sensor Actuat B, 2001, 76: 494

[29] Paixão T R L C, Bertotti M. J Electroanal Chem, 2004, 571: 101

[30] Cubeiro M L, Fierro J L G. Appl Catal A, 1998, 168: 307
[31] Fleischmann M, Korinek K, Pletcher D. J Electroanal Chem Interfacial Electrochem, 1971, 31: 39

[32] Iguchi K, Tachibana A. Appl Surf Sci, 2000, 159-160: 167

[33] Karim-Nezhad Gh, Seyed Dorraji P. Electrochim Acta, 2010, 55: 3414

[34] Jadhav R S, Hundiwale D G, Mahulikar P P. J Coat Technol Res, 2010, 7: 449

[35] Duran B, Turhan M C, Bereket G, Sezai Sarac A. Electrochim Acta, 2009, 55: 104

[36] Martins dos Santos L M, Lacroix J C, Chane-Ching K I, Adenier A, Abrantes L M, Lacaze P C. J Electroanal Chem, 2006, 587: 67

[37] Camalet J L, Lacroix J C, Aeiyach S, Chane-Ching K, Lacaze P C. Synth Met, 1998, 93: 133

[38] Herrasti P, del Rio A I, Recio J. Electrochim Acta, 2007, 52: 6496

[39] Situmorang M, Gooding J J, Hibbert D B, Barnet D. Biosensors Bioelectron, 1998, 13: 953

[40] Luo M Z, Baldwin R P.J Electroanal Chem, 1995, 387: 87

[41] Marioli J M, Kuwana T. Electrochim Acta, 1992, 37: 1187

[42] Wels B, Johnson D C. J Electrochem Soc, 1990, 137: 2785

[43] Burke L D, O’Dwyer K J. Electrochim Acta, 1991, 36: 1937

[44] Yoshizawa K, Kagawa Y.J Phys Chem A, 2000, 104: 9347

[45] Roslonek G, Taraszewska J. J Electroanal Soc, 1992, 325: 285

[46] Nozad Golikand A, Asgari M, Ghannadi Maragheh M, Shahrokhian S.J Electroanal Chem, 2006, 588: 155

[47] Ureta-Zanartu M S, Alarcon A, Munoz G, Gutierrez C. Electrochim Acta, 2007, 52: 7857

[48] Nicholson R S, Shain I. Anal Chem, 1964, 36: 706

[49] Randles J E B. Discuss Faraday Soc, 1947: 11 